\title{
CONDENSACIÓN Y ACUMULACIÓN DRAMÁTICA EN ANTÓN CHÉJOV
}

\section{Condensação e acumulação dramática em Anton Tchékhov}

\section{Dramatic condensation and accumulation in Anton Chekhov}

\author{
Nicholas Rauschenberg \\ Universidad de Buenos Aires - UBA
}

Resumen: A partir de una reconstrucción exhaustiva de las principales obras teatrales de Antón Chéjov, buscamos en este artículo pensar dos nociones imprescindibles para los dramaturgos: la condensación y la acumulación dramáticas. Después de pensar una dialéctica entre disociación y condensación, analizamos a Tío Vania y las obras posteriores, mostrando cómo Chéjov elaboró a partir de la reescritura de Fauno y La Gaviota una economía de personajes, vínculos y situaciones dramáticas de acumulación a partir de condensaciones más sofisticadas en los relatos.

Palabras claves: Antón Chéjov; Condensación dramática; Acumulación dramática; Disociación; Tío Vania.

Resumo: A partir de uma reconstrução exaustiva das principais peças de Anton Tchékhov, buscamos neste artigo pensar duas noções imprescindíveis para os dramaturgos: a condensação e a acumulação dramáticas. Depois de pensar uma dialética entre dissociação e condensação, analisamos Tio Vania e as obras posteriores, mostrando como Tchékhov elaborou a partir da reescritura de Fauno e A Gaivota uma economia de personagens, vínculos e situações dramáticas de acumulação a partir de condensações mais sofisticadas nos relatos.

Palavras-chave: Anton Tchékhov; Condensação dramática; Acumulação dramática; Dissociação; Tio Vania.

Abstract: Based on an exhaustive reconstruction of Antón Chekhov's main plays, we seek in this article to think of two essential notions for playwrights: dramatic condensation and accumulation. After thinking about a dialectic between dissociation and condensation, we analyze Tío Vania and the later works, showing how Chekhov elaborated from the rewriting of Fauno and La Gaviota an economy of characters, links and dramatic situations of accumulation from more sophisticated condensations in the stories.

Keywords: Anton Chekhov; Dramatic condensation; Dramatic accumulation; Dissociation; Uncle Vania. 
La extensa obra de Antón Pávlovitch Chéjov está compuesta en su mayor parte por cuentos y en menor medida por obras de teatro. Sin embargo, nos interesa aquí este segundo grupo. Las obras chejovianas no buscan una fábula que determine el sentido externo o simbolista en sus obras, sino que buscan armarse a partir de objetividades de los mundos de los personajes, también concisión temporal y economía de los hechos narrados. Para Chéjov, el arte puede representar fragmentos de la realidad, pero sin buscar relaciones inmediatas de causa y efecto, es decir, "sin respuestas definitivas para los conflictos y predispuesta a lo inesperado y a lo inexplicable" (CAVALIERE, 2009, p. 180). Las siete principales obras teatrales de Chéjov - Platonov, Ivanov, EI Fauno, La gaviota, Tío Vania, Las tres hermanas y Jardín de los cerezos tematizan encrucijadas de la vida de cierta aristocracia venida a menos, por así decirlo. El dispositivo central de las composiciones es un desplazamiento geográfico y cultural de uno o más personajes para contrastar con la vida y la decadencia inminente del estilo de vida de las viejas oligarquías campesinas. En general, el universo de los personajes de Chéjov se sitúa em

una casa de campo, el pesado tedio provinciano, personajes ociosos y sin voluntad, que sueñan bostezando con una vida mejor, pero que nada intentan para sacudir su inacción y, frente a ellos, hombres nuevos, realistas, voraces, dispuestos a cualquier cosa para asegurar su predominio; la falta de dinero, la mansión familiar y su hermoso parque a punto de ser vendidos para pagar deudas, la vodka corriendo a mares, el embotamiento de la ebriedad, los discursos vacíos y sonoros, los suspiros de las bellas damas mal amadas. (TROYAT, 1986, p. 48)

Antón Chéjov construyó en sus obras de teatro una condensación de personajes, vínculos, funciones dramáticas, acumulación dramática, temporalidades y géneros dramáticos. Buscaremos en este ensayo reconstruir la evolución de esos elementos en sus obras. Teniendo en cuenta que el universo rural y pueblerino crea un cierto límite para personajes arquetípicos (terrateniente endeudado, empleado de finca, médico visitante, joven enamorada, hombre enamorado desilusionado y celoso, etc.), nos interesa analizar las variaciones de 
roles y elaboraciones de los vínculos entre los personajes para entender la acumulación dramática en juego en las construcciones formales de las obras de Chéjov. En un primer apartado, teniendo en cuenta la noción de rizoma, presentaremos la dialéctica disociación-condensación a partir de la cual incursionaremos en las obras teatrales de Chéjov (I). En seguida, abordaremos La gaviota indagando sobre la búsqueda "disociación-condensación" a partir de las obras anteriores, a saber, Platonov, Ivanov y El Fauno (II). En seguida, nos concentraremos en analizar la condensación dramática en Tío Vania teniendo en cuenta El Fauno y La gaviota, buscando enfatizar el procedimiento de la "acumulación dramática" como un derivado compositivo de la condensación (III). Nuestra hipótesis es que las obras escritas teniendo en cuenta la condensación como principio compositivo tienen mayor fuerza dramática gracias a que la fuerza disociativa se traslada a la "indeterminación determinada" de los personajes, vínculos, incertidumbres metafísicas, la propia noción de representación teatral y la temporalidad en juego como parte de la condensación. Y una mayor condensación permite construir situaciones con mayor acumulación dramática. En la última parte comentaremos cómo Chéjov trabajó la acumulación dramática en Las tres hermanas y El Jardín de los cerezos para preguntarnos por el género teatral de este corpus de obras (IV).

\section{(I) Disociación y condensación}

En la práctica compositiva de la dramaturgia buscamos una oposición dialéctica entre disociación y condensación. Disociar nos permite desarrollar los mundos de los personajes, multiplicar las posibilidades de vínculos, jugar con la presencia fantasmagórica de objetos, agotar las relaciones de causa y efecto de modo a buscar multicausalidades o estados de ánimo que puedan generar transformaciones dramáticas, probar distintas temporalidades, recortes temporales y espaciales, jugar con ciertas características de los personajes e, inclusive, con el lugar donde suceden las acciones significativas de una potencial obra, y finalmente, con la búsqueda disociativa podemos incursionar en distintos 
géneros narrativo-dramáticos buscando texturas lingüísticas diversas para personajes y hasta para pensar en convenciones teatrales aunque todavía en estados rudimentales.

El dramaturgo usa e investiga una inmensa amplitud de repertorios para construir elementos que generarán caminos de disociación: noticias de diario, fragmentos de poesía, biografías, fragmentos o síntesis de cuentos, frases oídas en algún medio de transporte público o de algún familiar, una memoria de alguna situación, cuadros, fotografías, un dibujo animado visto al azar en la televisión, un diccionario de lunfardo, una película antigua, una imagen disonante, una serie de metáforas, entre otras infinitas fuentes de elementos para generar vínculos disociativos, es decir, una tensión que el cerebro quiere aproximar, pero que el ímpetu compositivo del dramaturgo quiere persuadir a desestructurar y crear caminos de infinitud. La consigna sería nunca cerrar una idea como "representación" fija de un determinado estado de cosas, sino, más bien, dejarse llevar por las indeterminaciones materiales de los personajes, sus vínculos, su mundo contradictorio, sus estados emotivos, sus deseos más íntimos e innombrables, sus resentimientos, su clase social, su deseo de venganza o justicia, etc.

Disociar significa, por lo tanto, nunca cerrar una idea, siempre dudar de lo que aparentemente quiere cerrarse. En definitiva, el procedimiento de disociación podría definirse como un rizoma: "conexiones heterogéneas, eslabones impensados, multiplicidades de sentidos, ruptura asignificante y no correspondencia con ningún modelo estructural o generativo" (DELEUZE y GUATTARI, 2002, p. 25). A ese potencial infinito de disociación el dramaturgo le debe imponer un límite en forma de paradoja. Por un lado, de todos los procedimientos disociativos algo original surgirá, se creará alguna instancia de estructuración solo detectable a posteriori. Disociar pensando en una "idea" o estructura vincular o conflicto es contraproducente. La pregunta sería: ¿cuándo hay que parar? En el arduo intento de saber si detenerse o no con la disociación, el dramaturgo busca una abstracción del proceso que contenga, en la determinación del resultado, elementos, preguntas y lagunas de la fuerza 
disociativa que generó el resultado. Por otro lado, un buen proceso de disociación, cuando crea un buen resultado a partir de un recorte de su producto final, no se detiene. En razón de ese recorte - esa condensación que elige con precisión el resultado de las búsquedas disociativas - la fuerza rizomática no puede detenerse. Una buena condensación - restricción, recorte, abstracción, etc. - no detiene la disociación, sino que potencia su efecto disociador desde la contingencia.

El resultado final de la condensación jamás podría ser la representación de un pensamiento predeterminado o una idea concebida de antemano. El proceso de composición rizomático no puede ser una demostración de una noción socialmente justificable, es decir, no dibuja una posición política o crítica frente a otra, sino que abre un camino amplio y desconocido más allá de cualquier opinión o idiosincrasia previa. Nuestra paradoja consiste entonces en, por un lado, detener el proceso de disociación y recortar de modo contingente su resultado, es decir, poner una mirada de matemático a lago que se dibujó rizomáticamente desde otras lógicas. ¿Qué consideramos una condensación aceptable de un proceso disociativo? Sin embargo, por otro lado, esa condensación no es una detención, una parálisis del proceso de disociación, sino una continuación - por otros medios (puesta en escena, interpretación actoral etc.) - de fuerzas disociadoras. El resultado condensado impone paradojas porque todavía carga la indeterminación del proceso que condujo hacia él. Disociar y condensar, como dialéctica, son infinitos. Lo que cambia son los medios y las contingencias, los deseos poéticos y los límites del campo artísticos que impregnan las pretensiones e ilusiones del artista.

\section{(II) Primera fase: búsqueda disociativa}

La primera gran característica de los vínculos entre los personajes de las obras de Chéjov es el amor no correspondido como motor dramático. Aquí empieza Chéjov su proceso de búsqueda disociadora: para los deseos no correspondidos es preciso "crear mundo", es decir, desarrollar el contexto íntimo y 
social de los personajes. ¿Qué roles sociales tienen esos personajes? ¿Qué sistema de vínculos busca construir Chéjov con esas figuras? En Platonov (drama en cuatro actos), escrita aproximadamente en 1878, vemos a un profesor de una escuela provincial en la zona rural. Podría decirse que Platonov parodia de cierto modo a Don Juan. Platonov es deseado por todas las personajes de la obra. Siempre entre el ensueño y la borrachera Platonov se esquiva de las consecuencias de su seducción. Su presencia como hombre culto y sujeto deseado desequilibra todos los vínculos de su entorno. Ese desplazamiento es revelador del desencanto de los personajes que buscan desesperadamente, en su interior, que algo suceda, que algo cambie o se solucione. El amor no correspondido conduce a la tragedia. Sasha, esposa de Platonov, se suicida cuando se entera que su marido la traiciona. Sofía rompe su casamiento con Voinitzev con esperanzas de escaparse con Platonov. Anna Petrovna, joven viuda de un general, le propone una relación amorosa a Platonov. María Efímovna, una joven del pueblo y enamorada, decide denunciar a Platonov por sentirse seducida y despreciada de modo humillante. El protagonista durante toda la obra seduce y fracasa en cada amor. Le falla a su esposa y no consigue corresponder concretamente a ningún otro amor. En el final, Sofía, arruinada y desesperada, le dispara a Platonov. Le erra el primer disparo, pero no el segundo. Nicolai Ivánovich, joven médico y cuñado de Platonov, le omite ayuda en venganza por la muerte de Sasha. Es como si el joven médico que en ese momento era el propio Chéjov pudiese entrar en escena y hacer justicia por toda la maldad del protagonista.

Ivanov (drama en cuatro actos), escrita en 1887, también tiene un médico como personaje: Eugene Lvov. Esta obra trae a escena el gran error de Ivanov: se enamoró y se casó con Ana Petrovna, la mujer que amaba y en razón de la cual sería de paso premiado con una buena dote. Sin embargo, Ana era judía y para casarse con Ivanov se convirtió al cristianismo ortodoxo y fue renegada por su familia de origen. Con eso Ivanov nunca pudo recibir la dote y entró en bancarrota. El error catastrófico de Ivanov se completa con el enamoramiento que siente por Sasha, la hija de Zinaida Lebedeva, con quien el protagonista está 
fuertemente endeudado. Un potencial casamiento entre Ivanov y Sasha sería muy conveniente: eliminaría las deudas y recobraría al menos parcialmente el estatus social de mediana aristocracia. Por su parte, Ana Petrovna padece de tuberculosis y el médico Eugene Lvov se irrita con Ivanov que ignora - a pedido de Ana - el estado de su esposa y manifiesta una actitud de omisión y abandono hacia ella. Se pasa gran parte del tiempo en la casa de Sasha en reuniones y fiestas. Eugene Lvov le explica a Ivanov que Sasha, para recuperarse, debe tener una larga estadía en Crimea. Ivanov dice que ese viaje sería impagable. En el segundo acto, Ivanov concurre a una fiesta y besa a Sasha. Eugene Lvov, indignado, acompaña a Ana Petrovna a la fiesta y entran de sorpresa y testifica la traición de su marido. En el tercer acto todos los conflictos se intensifican. Ante la incertidumbre por el nuevo casamiento, el padre de Sasha, Pavel Lebedev, le pide a Ivanov que salde sus deudas. Por otro lado, Eugene vuelve a exigirle a Ivanov que se ocupe de su esposa. Sasha también le pide al protagonista que retomen su relación prohibida. Ana Petrovna le revela a Ivanov que se está muriendo y que su enfermedad ya no tiene cura. En el último acto, ya pasado un año desde el final del acto anterior, nos enteramos que Ana ha muerto y que ya está todo listo para el casamiento entre Ivanov y Sasha. Sin embargo reaparece Eugene Lvov y acusa públicamente a Ivanov de su omisión ante la enfermedad de su difunta esposa. Muchos de los conocidos defienden a Ivanov, sobre todo para no deslegitimar el casamiento. Al ver la humillación y quizás corroído por la culpa, Ivanov agarra un revólver, se escapa de la multitud y se suicida.

En La gaviota, escrita en 1896, es como si, además del personaje del médico - aquí el personaje de Eugeni Dorn -, se sumara el de un escritor - Boris Trigorin - en una suerte de doble alter ego chejoviano. El protagonista es Konstantín Tréplev (Kostia), un joven dramaturgo - ¿otro alter ego? - hijo de la famosa actriz Arkádina. La idea de "gaviota" parece estar referida al personaje de Nina y su vínculo con Tréplev. La gaviota cuenta la historia de cinco amores no correspondidos. Primero, Masha, hija de los administradores Shamréiev y Polina, quiere en secreto a Tréplev. Segundo, Nina, joven actriz, rechaza el amor de Tréplev, que la ama con locura, porque quiere a Trigorin. Tercero, Trigorin 
rechaza a Nina pese a tener una breve relación con ella, inclusive un bebé. Trigorin es el novio de Arkádina, madre de Tréplev, con quien consigue una estabilidad económica y ser parte de un ámbito socio-cultural establecido. En cuarto lugar, Medvedenko, el personaje del maestro - que apareciera en Platonov - también aparece aquí aunque con poco protagonismo, ama a Masha. Ésta se casa con él, pero sin amor, para tratar de olvidar a Tréplev. Finalmente, Polina Andréievna, esposa Shamráiev, administrador de la finca de Arkádina, quiere al médico Eugeni Dorn, que la rechaza.

En el primer acto, Tréplev espera a Nina en un escenario a la orilla del lago para que ella represente un monólogo escrito por él. Tréplev le declara su amor a Nina y ella se desentiende y manifiesta su admiración por Trigorin, aun sin haberlo visto antes. Tréplev se pone celoso. Luego Nina declama el pretensioso texto de Tréplev y es interrumpida primero por los comentarios ácidos de Arkádina, y luego por el propio Tréplev que se siente humillado por su madre y suspende la función ya en marcha. Arkádina le presenta a Nina su novio Trigorin. Sorin, el hermano de Arkádina, por lo tanto, tío de Tréplev le reprocha a su hermana la actitud mezquina que esta tuvo con su hijo. Es como si ella no pudiera soportar que su hijo creciera y buscara un lugar que pudiera amenazar su estrellato. Además, Tréplev sólo quería llamar la atención y tener algún reconocimiento más desde la afectividad que desde una gran pretensión estética. El médico Dorn, después de la despedida de Nina, elogia a Tréplev y lo encoraja a seguir en el teatro con comentarios muy precisos y contundentes sobre su obra y el arte. Tréplev, sin embargo, quiere ir a buscar a Nina. Finamente, Masha le confiesa a Dorn que está enamorada de Tréplev.

En el segundo acto, Arkádina se pelea con Shamráiev, administrador de la finca que pertenece a ella y a su hermano Sorin. Arkádina quiere ir a la ciudad cercana a la finca pero Shamráiev no quiere disponibilizar los caballos de paseo porque justo ese día se acarrea el centeno y todos los caballos están siendo utilizados. El administrador amenaza con renunciar y la dueña amenaza con irse de vuelta a Moscú. Polina Andréievna le pide a Dorn que se la lleve con él a vivir a otro lugar. Dorn parece corresponder parcialmente a la pretensión amorosa de 
Polina, pero le dice que prefiere seguir como están, ya que él tiene cincuenta y cinco años. Polina le recrimina a Dorn que éste tiene otras amantes en los pueblos vecinos y que ella lo aburre por ser solo una más. Ese comportamiento de Dorn - generar muchos deseos y aprovecharse parcialmente de ellos - nos remite al personaje central de Platonov. El acontecimiento central del acto dos es el encuentro casi desastroso entre Nina y Tréplev que es interrumpido por Trigorin. Este segundo encuentro define el amor entre Nina y Trigorin, única pasión simétricamente mutua en la obra. Tréplev trae una gaviota muerta y se la ofrece a Nina. Ambos se recriminan cierta distancia pero Tréplev exagera en su victimización diciendo que su obra no ha agradado a nadie. ¿Sería la gaviota muerta el amor muerto entre Tréplev y Nina? Entra Trigorin y al verlo, Tréplev se escabulle dejándolo a solas con Nina. Trigorin la galantea y Nina le expresa su admiración por sus novelas. Trigorin quiere desentenderse de la fama y en seguida cuenta su procedimiento de composición como un activo "depósito literario", siempre atento a las palabras dichas y a las necesidades puntuales de lo ya escrito. Se pasa "de un libro a otro sin interrupción", dice. Trigorin mira el lago y le pide a Nina que ayude a convencer a Arkádina para que se queden algunos días más en la finca. Ambos están ya enamorados.

El tercer acto empieza con Masha comentándole a Trigorin su amor secreto por Tréplev. Ha pasado una semana desde que Nina y Tréplev se enamoraron. En su primera réplica nos enteramos que el hijo de Arkádina intentó suicidarse, pero que está bien. Masha le confiesa a Trigorin que se casará con el maestro Medvedenco: "Cuando me case, no habrá tiempo para el amor; nuevas preocupaciones ahogarán todo lo viejo" (CHÉJOV, 2013, p. 117). Como hay valijas y se habla en un tono de despedida, percibimos que Trigorin y Arkádina se está por volver a Moscú. Todo este acto gira en torno a esa despedida. ¿Por qué se van? Trigorin le cuenta a Masha que Tréplev lo retó a duelo, y eso hace ineludible la necesidad de irse. Masha le dice que esas actitudes de Tréplev se deben a los celos por Nina. Entra Nina astutamente y le pide a Trigorin que hablen dos minutos a solas para despedirse. Al escuchar que viene Arkádina, Nina sale. Sin embargo Arkádina se da cuenta y Trigorin se lo confirma. Sorin le 
pide a su hermana que le de algún dinero a Tréplev para que pueda restablecerse, comprarse ropa y poder salir un poco de la finca. Arkádina se niega con mezquindad.

Entra Tréplev con la cabeza mal vendada, como un turbante, y le pide a su madre que le acomode la venda. Tréplev le promete a su madre no volver a intentar el suicidio, y vemos que ella tiene más bien una actitud de esquivar la profundidad de la situación. Prefiere huir y llevarse a Trigorin como si éste fuera la única causa de los males de su hijo. Arkádina se lleva a Trigorin para preservar su relación con él y alejarlo de Nina. Trigorin le pide a su novia que lo deje enamorarse de Nina. Trigorin: "Un amor joven, encantador, poético, que nos lleve al mundo de los sueños, sólo un amor así puede darnos felicidad en la tierra. Yo no le he conocido nunca... En mi juventud no tuve tiempo, gastando los umbrales de todas las redacciones, luchando contra la miseria... Ahora, por fin, este amor ha llegado, me llama... ¿Por qué he de huir de él?" (CHÉJOV, 2013, p. 124). Arkádina se humilla y le pide para que se vayan y termine el romance con Nina. Trigorin alega que nunca puede actuar por propia voluntad: "Flojo, fofo, siempre dócil. ¿Es posible que esto pueda gustar a una mujer? Tómame, llévame, pero no me dejes que me aparte de ti ni un paso" (CHÉJOV, 2013, p. 125). Arkádina lo abraza y le dice, como quien juega al póquer: "Si quieres, puedes quedarte. Me voy sola y tú vienes después, dentro de una semana. $Y$, en realidad, ¿qué apuro tienes?" (CHÉJOV, 2013, p. 125). Trigorin decide irse con ella. Polina trae ciruelas para el viaje y Shamráiev anuncia que el coche y los caballos ya están listos y cargados. Todos salen pero Trigorin vuelve. Aparece Nina que le anuncia que irá a Moscú a estudiar teatro. Se abrazan y besan, alegres por saber que se volverán a ver.

El cuarto acto nos lleva a la misma finca dos años después. Entran Masha y Medvedenco. Nos enteramos que ya están casados y tienen un bebé que se quedó en la casa con su ama de leche Matriona. Masha parece tener una crisis de angustia y abstinencia por Tréplev, quien le sigue siendo indiferente. Polina le comenta a Tréplev que está sorprendida con sus progresos en el mundo de las letras y le pide que sea más cariñoso con su hija Masha. Tréplev sale ignorando 
la situación, con cierto desprecio. Polina le dice a su hija que está preocupada con ella, que entiende que ese amor no correspondido la carcome. Masha trata de negarlo: "Tonterías. El amor desesperado no existe más que en las novelas. Pavadas. Pero no hay que abandonarse ni estar siempre esperando algo, estarse sentado esperando a que escampe... Si una vez el amor penetró en el corazón, hay que arrancarlo. Nos han prometido trasladar mi marido a otro distrito. Cuando nos mudemos allí, lo olvidaré todo... lo arrancaré de raíz del corazón" (CHÉJOV, 2013, p. 130). Esta negación desesperada y el olvido necesario pero imposible es un preludio para la situación de Kostia (Tréplev).

Entran Medvedenko y Sorin, que pregunta dónde está su hermana. Dorn le dice que fue a la estación a buscar a Trigorin. Por eso no hay un caballo para que Medvedenko vaya a su casa, a seis quilómetros de la finca. El marido de Masha decide irse a pie. Dorn le pregunta a Tréplev por dónde anda Nina. Tréplev le contesta que ella tuvo un chico, pero que ha muerto. El chico era de Trigorin, quien la abandonó y volvió a estar con Arkádina. Kostia cuenta, además, que ella es una actriz que hace temporada en alguna provincia y la seguía, pero ella lo evitaba. Nina interpretaba sus papeles con alaridos y movimientos exagerados, cuenta Tréplev. Nina le escribió algunas cartas y firmaba "Gaviota". Kostia cuenta también que Nina está en la ciudad, cerca de la finca, desde hace cinco días, y la fue a ver pero ella insiste en no ver a nadie. Llegan Arkádina y Trigorin, que saluda a todos como si solo el tiempo hubiera pasado. Trigorin le regala a Tréplev una revista donde se ha publicado un cuento del hijo de Arkádina. Trigorin le dice que se quedará un solo día en la finca. Polina los invita a jugar al bingo antes que esté lista la cena. Durante el juego Dorn comenta que le tiene fe al oficio de escritor de Tréplev: "Piensa con imágenes, sus cuentos son pintorescos, fuertes; los siento interesantemente. Lástima que no tenga fines definidos. Produce impresión y nada más, pero con la impresión solamente no se va muy lejos" (CHÉJOV, 2013, p. 137).

Tréplev decide no ir a comer y se queda solo en su amplio despacho, donde dos años antes era la sala de reuniones. En un breve monólogo reconoce que Trigorin tiene una metodología más sofisticada en su escritura: "Brilla en la 
represa el cuello de una botella rota y ennegrece la sombra de la rueda del molino; y ya tiene lista la descripción de una noche de luna. Mientras que yo, la luz temblorosa, y el quieto fulgor de las escenas, y los lejanos sonidos del piano que mueren en el quieto aire perfumado... ¡Es torturante!" (CHÉJOV, 2013, p. 138). Aparece Nina por la ventana y Tréplev la va a buscar. Entran y se abrazan. Ella llora. A pedido de Nina, Tréplev bloquea la puerta de la izquierda que da al salón donde los demás están cenando. Kostia le pregunta por qué ella no le permitió verla y ella le dice que temía que él la odiara. Mañana Nina ya tendrá que partir para una temporada teatral de invierno en Elets. Kostia le dice que la odió y rompió sus cartas, pero que la sigue amando: "Sufro... Mi juventud me fue arrancada de golpe, y me parece que hace noventa años que vivo en el mundo. Yo la llamo, beso la tierra que usted ha pisado; dondequiera que miro se me aparece su rostro, esa sonrisa cariñosa que me iluminaba en los mejores años de mi vida" (CHÉJOV, 2013, p. 139). Nina prepara para irse, pero cuando se pone el sombrero y la capa le pregunta a Kostia si su madre está. En ese momento se escuchan risas y Nina reconoce la risa de Trigorin y cambia su mirada:

Él [Trigorin] no creía en el teatro, siempre se reía de mis sueños y, poco a poco, yo también dejé de creer y cayó mi ánimo. Además, las preocupaciones del amor, los celos, el continuo miedo por la criatura... Me volví mezquina, insignificante, trabajaba sin ningún sentido... No sabía qué hacer con las manos, no sabía estar en el escenario, no dominaba mi voz. Usted no sabe lo que es ese estado, saber que se actúa horriblemente. Soy una gaviota. [...] Ahora soy distinta. Ya soy una verdadera actriz, trabajo con fervor, con pasión, experimento una embriaguez en el escenario, me siento hermosa. $Y$ ahora, mientras vivo aquí, siempre ando y ando, y pienso, pienso y siento crecer cada día las fuerzas de mi alma. Ahora, Kostia, yo sé, comprendo que en nuestro oficio, tanto si trabajamos en el escenario como si escribimos, lo principal no es la gloria, ni el brillo, todo eso con lo que soñaba, sino el saber soportar... Saber llevar la cruz y creer... Yo creo y no siento ya tanto dolor, y cuando pienso en mi vocación, no temo a la vida. (CHÉJOV, 2013, p. 140) 
Kostia, desconsolado, le dice que ya no sabe en qué consiste su vocación. Nina insiste en irse, pero él le ofrece algo de comer. Ella rechaza la comida y comenta que Arkádina trajo a Trigorin consigo. Le pide a Kostia que no le diga nada a Trigorin de su visita. Dice que todavía lo quiere, quizás aún más que antes. Nina: "Lo quiero, lo quiero con pasión, lo quiero desesperadamente" (CHÉJOV, 2013, p. 141). Después de recitar un pasaje de la obra que escribió Tréplev y que fue interrumpida por la pelea entre Arkádina y su hijo, Nina sale corriento. Tréplev mira sus manuscritos y los va rompiendo de a uno, va hacia la puerta de la derecha y sale. Dorn intenta abrir la puerta de la izquierda y entra, seguido por Arkádina, Polina, Shamréiev y Trigorin. Shamréiev le muestra a Trigorin una Gaviota embalsamada, la que mató Kostia. Trigorin no recuerda habérselo pedido. De repente se escucha un tiro del lado derecho, Kostia se ha suicidado.

\section{(III) Segunda fase: condensación y acumulación dramática}

No nos importa aquí tanto la recepción que tuvo La gaviota en el año de su estreno y la difícil relación entre Stanislávski y Chéjov sobre los matices interpretativos de sus obras (GUINSBURG, 1985). Basta decir, y esto si nos interesa como disparador, que el director ruso estaba impregnado de un realismo naturalista que Chéjov rechazaba por preferir una puesta mucho más distendida y graciosa. El propio Stanislávski (2013) cuenta las reacciones de reproche de Chéjov al ver sus obras y extrañar su trabajo en ellas. El autor se quejaba que el director les cambiaba el género dramático. De comedias - influenciadas por el vaudeville, tan caro a Chéjov - el director las transformaba en dramas. El caso más notable es sin dudas El jardín de los cerezos, como veremos más adelante. ¿En qué nos compete esta fisura? Por el potencial disociador-condensador de las obras chejovianas. Si bien La gaviota trae al lector un potencial enorme de condensación dramática, es a partir de Tío Vania, escrita en 1900, que vemos el uso de ese procedimiento definido como característica formal que conduce a un efecto deseado: la acumulación dramática. Nuestra hipótesis es que Chéjov, en 
Tío Vania, retoma los personajes de El Fauno - los Serebriakov - a la luz de la estructura dramática de los personajes de La Gaviota. No se trata de una trampa del autor ruso, sino más bien de una búsqueda. Por algún motivo Tío Vania no sólo es una de las obras de Chéjov más llevadas al escenario - por lo menos en Argentina - y que genera muchas variantes como Penas sin importancia (1990), de Griselda Gambaro (2008), y Espía una mujer que se mata (2007), de Daniel Veronese, cuyo texto aún no ha sido publicado.

Los personajes de El Fauno (CHÉJOV, 2014), escrita en 1889, que forman Tío Vania, escrita en 1899, son: el profesor Alexandr V. Serebtiakov; su mujer Elena Andréievna, de 27 años; Sonia, la hija del profesor; Voinitski (o Tío Vania), tío de Sonia; María Vasilievna, madre de Vania; y Astrov, el médico, que en la versión anterior era el Fauno. Se preservaron de El Fauno, por lo tanto, los personajes del núcleo familiar de los Serebriakov, por así decirlo, además de Marina, la anciana nodriza, y de un peón. La gran fuerza dramática proviene de Elena y Astrov: Elena es pretendida por Vania y Astrov, y Sonia y Elena quieren a Astrov. El tema del amor imposible pero deseado sigue siendo el motor de la acción dramática, pero en Tío Vania ya no tenemos un círculo tan extenso y de cierta forma repetitiva como en Platonov o La Gaviota, donde ese circuito de desamor repite cierto estándar o anticipa modalidades, como vimos con Masha y Tréplev en La gaviota. En La gaviota, el único amor que se realiza es aquél entre Nina y Trigorin, pero parece fracasar por las circunstancias del embarazo de Nina. Pero Nina lo sigue amando y es posible que Trigorin también. En Tío Vania, Elena y Astrov se quieren pero Elena rechaza la posibilidad de una relación con el médico, que implicaría abandonar a su marido. En El Fauno, Elena abandona a Serebriakov un poco por desamor, un poco por las calumnias de Fiódor y principalmente por el suicidio de Vania. Los conflictos en El Fauno son muy fuertes y quizás exageradamente desproporcionados: una conspiración con cartas, un suicidio, un abandono de hogar que después fácilmente se revierte. En Tío Vania Chéjov resuelve algunas de esas inconsistencias desde las acciones dramáticas del mundo de los personajes. Veamos cómo lo hace. 
En el primer acto, Astrov habla con Marina sobre la saturación de su trabajo, sus decepciones y la falta de sentido de su sacrificio ante tanta miseria e ignorancia. Ya no es tan autosuficiente y quizás soberbio como en El Fauno. Cuando entra Voinitski en escena, lo que nos trae es que el principal motivo que lo aqueja es la presencia de Serebriakov y Elena, el mundo está fuera de sí, ya no consigue trabajar y los horarios de la casa están todos modificados en razón del viejo profesor que decidió instalarse para siempre en la finca. Vania ya no compite con Fiódor por Elena, sino con Astrov, que es el médico que atiende a Serebriakov y que es amado por Sonia. El nuevo mapa de vínculos genera un sistema más económico, más intenso y mucho más definido desde cada personaje, su profundidad y su particularidad. Esta densidad dramática permite que las réplicas expliquen menos, que las actuaciones puedan investigar nuevos registros y que lo importante en la obra esté en lo no-dicho. Esta es la condensación que genera un despliegue de otras disociaciones que exceden la dramaturgia.

Serebriakov llega ya no esperando a terratenientes más poderosos como Sheltujin, al que le ofrece comprar su finca, y Orlovski de El Fauno, sino con el pobre y decadente Teleguin que recuerda al inquilino lliá Diadin (el "Barquillo") de El Fauno. El status de casi celebridad de Serebriakov está fortalecido en Tío Vania. En El Fauno Serebriakov había vendido cuatro mil rublos de bosque para desesperación y reproche del médico Jrushov, pero ahora es él la autoridad máxima en escena. Serebriakov condensa no solo la posición de dominación socio-económica, sino también el status cultural. Si pensamos en La Gaviota, Serebriakov tendría un claro paralelismo con Arkádina: una actriz famosa y rica, y al mismo tiempo terrateniente junto a su hermano Sorin. Si seguimos con los paralelismos entre personajes de ambas obras, podríamos decir que Voinitski se parece a Tréplev porque el amor no correspondido se potencia con una decepción de la vida en razón de su vocación inexpresiva. Tréplev se mata al final, y Vania se resigna. Esa resignación en lugar de un suicidio le da mundo al personaje. Tréplev cree en la gloria del arte como un romántico. Le duele que Nina sea más realista y haya aprendido a vivir el arte desde el oficio, sin expectativa de tener 
gloria desde "la genialidad" que le atribuye la fama a Arkádina o a Trigorin. Voinitski ama a Elena y ese amor lo hace ver que desperdició su vida manteniendo la finca para ayudar económicamente a Serebriakov. Ya no estamos en un extremo entre la vida y la muerte, sino ante un personaje con objetivos y frustraciones en juego. En El Fauno, Voinitski se victimiza, se siente traicionado cuando Serebriakov anuncia que quiere vender la finca y se suicida. En Tío Vania Voinitski enfrenta a Serebriakov y le dispara dos tiros aunque los erre. Es otra actitud. Ya no el suicidio trillado como en Ivanov o La gaviota. El peligro de muerte no viene de la introspección o culpa autoflagelante del personaje, sino de la acción dramática en juego en los vínculos y los deseos objetivos. Y el no suicidio descarga la obra de solemnidad y abre el drama: puede ser hasta una comedia o una comedia-trágica.

El primer acto concluye con la admiración de Sonia por Astrov, tal como en El Fauno. También vemos la rivalidad entre Astrov y Vania en torno a la necesidad del médico en preservar los bosques y replantarlos. Finalmente Vania avanza sobre Elena, pero no ya excesivamente borracho y amargado como en El Fauno, sino que le pide poder aunque sea hablar de su amor por ella. Vania tiene mucho más particularidad en su personaje. Si pensamos en el paralelismo con $\mathrm{La}$ Gaviota, Vania estaría para Tréplev. Voinitski está a la sombra de su cuñado Serebriakov y pierde la mujer amada para Astrov, que ocupa el lugar dramático de Trigorin. Pero en vez que poner un personaje como Masha que es inferior socialmente y ama a Tréplev, Chéjov, en Tío Vania, evita el espejismo de vínculos y trae de El Fauno el amor de Sonia por Astrov que no será correspondido. En El Fauno, Sonia rechaza al rico terrateniente Leoníd S. Sheltujin que, como en Ivanov, resolvería cualquier inconsistencia económica; Sonia "se sacrifica", por así decirlo, para quedarse con el misterioso Fauno.

Por otro lado, nadie ama a Voinitski - ni en El Fauno ni en Tío Vania - y el círculo del desamor se interrumpe. El sistema de vínculos deja de ser circular basado en desamores espejados y pasa a construir relaciones con más matices que la sola jerarquía social y los reconocimientos vanagloriosos de una Arkádina o un Trigorin. Elena proviene de la alta clase, Serebriakov es un aristócrata 
decadente, Astrov es un profesional de la medicina con una pequeña finca, Sonia es heredera así como Vania. La admiración que puede causar Serebriakov le juega en contra: todos, hasta su propia esposa, están hartos de él. Los vínculos se juegan desde objetivos más precisos y particulares. La condensación aporta personajes más sólidos en la acción y no en su subjetivismo, por eso la economía de vínculos es más estrecha y efectiva: pone la lupa en lo que sucede no solo en escena, sino también fuera de ella. Es mucho más dramático lo que se quiere y no se puede hacer; lo que se debe hacer, por un lado, contrapuesto a lo que se desea hacer pero es imposible, por otro.

A los dramaturgos se les enseña, por así decirlo, a no crear circunstancias externas a los personajes que puedan inviabilizar los preconflictos y las características de los personajes. El ejemplo magistral es La tempestad de Shakespeare: La tempestad es absolutamente condicionante para la obra, pero es fruto de la magia de Próspero. En el realismo expresionista de Chéjov el clima es más discreto. En el segundo acto de Tío Vania - que coincide en un noventa por ciento con el acto segundo de El Fauno - está habitado por una tormenta nocturna de verano. No es ni un diluvio ni tan solo una lluvia liviana. El cambio de clima ataca el reumatismo de Serebriakov y esto genera que los personajes, con sus deseos y frustraciones, tengan que interactuar. Sonia tiene que mandar a llamar a Astrov. Elena tiene que cuidar a su marido que se queja de la vida y la hace enfadarse. El viejo profesor no quiere que Vania lo cuide porque le tiene miedo. Voinitski se autorecrimina no haber intentado conquistar a Elena diez años antes cuando ella todavía era adolescente y soltera. Llega Astrov después de haber enfrentado en el camino a la tormenta. Viene un poco ebrio. Astrov sabe que Vania también quiere a Elena.

Astrov: ¿Por qué estás tan triste hoy? ¿Te da lástima el profesor, o qué? Voinitski: Déjame. Astrov: ¿O es que estás enamorado de la profesora? Voinitski: Somos solamente amigos. Astrov: ¿Ya? Voinitski: ¿Qué significa ese 'ya'? Astrov: La mujer puede llegar a ser amiga de un hombre sólo en el siguiente orden: primero, agradable conocida; después, amante y sólo más tarde, amiga. (CHÉJOV, 2013, p. 161)) 
En El Fauno, esta escena se da entre Fiódor, que también quiere a Elena, y Voinitski. Aquí, la condensación dramática del autor hace que Fiódor se incorpore al personaje de Astrov. Esta absorción reconfigura la fuerza dramática de los objetivos del médico. Astrov, que en El Fauno apenas esboza una admiración, aquí quiere a Elena desesperadamente y se lo hace saber a Vania.

Cuando llega Sonia llega le recrimina a su tío que está borracho y abandonó en sus manos el cuidado de la finca. Vania, al salir, sostiene un llanto, posiblemente por celos de Astrov o por alguna otra frustración. Eso seguramente queda a cargo de la interpretación del texto de cada actor o director. Sonia llama a Astrov que está poniéndose la corbata en otra habitación. En esta conversación, Sonia le pregunta al médico: "qué le pasa con mi madrastra". Astrov reconoce que siente seducido por belleza de Elena. Sin embargo, para despistar las intenciones de Sonia, Astrov simula que está desilusionado de la vida: "El destino me golpea sin cesar; a veces sufro de un modo insoportable, pero no tengo ninguna lucecita a lo lejos. Para mí ya no espero nada, no quiero a la gente... Hace tiempo que no quiero a nadie” (CHÉJOV, 2013, p. 163). “¿A nadie?”, le pregunta Sonia. Astrov usa subterfugios para despistar lo que él sabe que Sonia quiere oír. No la quiere decepcionar. Astrov decide irse, y Sonia lo detiene. Le pregunta si quizás una amiga o hermana quisiera algo con él, cómo reaccionaría. Astrov entiende aún más claro la situación. Dice que no puede querer a nadie y sale. Aunque lamente ser fea, Sonia se siente feliz por estar enamorada de Astrov. En El Fauno, esta conversación es mucho más larga y, pese a que las didascálias son muy acotadas, se da a entender que ellos se besan. En Tío Vania, Astrov es más rústico, más misterioso, tiene un objetivo más claro. Finalmente, entra Elena diciendo que la tormenta ha terminado y le pide a su hijastra que hagan las paces de una buena vez. Comparten una copa de vino. Se emocionan. Sonia le pregunta si ella quiere a Astrov y Elena asiente. Sonia le cuenta lo tanto que le gusta el doctor. Elena entiende que si decide quedarse con el doctor, le romperá el corazón a su hijastra.

Como suele suceder en las obras de Chéjov, el tercer acto se forma por la cima de los acontecimientos, por acciones irreversibles y transformaciones 
dramáticas potenciadas en los dos actos anteriores. En El Fauno, el tercer acto tiene quince escenas, mientras que en Tío Vania hay solo cinco. ¿A qué se debe esta condensación? La gran diferencia entre los actos terceros de El Fauno y Tío Vania es la acumulación dramática que conduce hacia el desenlace. La acumulación se debe a una yuxtaposición de síntesis que conducen a que el desenlace sea más potente por sobreponer al menos dos capas de significación. En El Fauno hay un exceso de tensiones desparramado en los muchos personajes: Fiódor quiere a Elena, conspira falsificando una carta de Voinitski donde este contaría sus aventuras con Elena; además, Fiódor también menciona que se casaría con lulia. lulia, a su vez, le pide a Sonia que se case con Sheltujin. Acción que el propio Sheltujin le reprochará a su hermana menor (Iulia). Sonia rechaza la oferta de casamiento. En seguida, entra Elena y Sonia le recrimina la carta que dejó maliciosamente Fiódor firmada por Voinitski. A continuación, Fiódor se le acerca a Elena y le dice que lo espere atrás del jardín y que finalmente podrán estar juntos. Elena lo rechaza con vehemencia y lo echa de la casa. Sheltujin reta a su hermana porque Serebriakov quiere venderle la finca dando por sentado que ese gesto se debe a que el profesor ya sabe que Sonia y Sheltujin se casarían. Recién en la décima escena viene Serebriakov a hacer el anuncia de que conviene vender la finca y aplicar el dinero en acciones porque eso será más rentable y podrán vivir en la ciudad. En el anuncio, Serebriakov también dice que ya vendió cuatro mil rublos de bosque para la tala porque la plata no alcanza. Voinitski se enoja y argumenta que él también es dueña de la finca porque desde un principio había deudas y él trabajó para pagarlas. Voinitski le reprocha a Serebriakov que este le arruinó la vida, que dio la vida para mantenerlo en la ciudad y que lo admiraba, pero que ahora lo desprecia: "Escribes sobre arte, pero no entiendes nada de arte" (CHÉJOV, 2014, p. 457).

Serebriakov pide que lo alejen de Voinitski y Elena amenaza con irse por su indignación por la travesura de Fiódor. Ya en la escena doce entra el Fauno o Jrushov para persuadir a Serebriakov con su filosofía a que retroceda en la venta del bosque. Serebriakov tiene la acumulación de todo el reproche de Voinitski en torno a la venta de la finca. Serebriakov (a Jrushov): "Y le pido que me deje en 
paz con sus salidas de psicópata" (CHÉJOV, 2014, p. 459). Sonia aborda a Jrushov que está enojadísimo para hablarle de su amor por él. Jrushov le dice que terminen cualquier relación posible. Con el corazón partido, Jrushov todavía se cruza con Elena y ésta le dice que lo quiere: "Mi alma le pertenece". Elena quiere proponerle amistad, a lo que él responde grosero: "Apártese de mí... ¡Desprecio su amistad!” (CHÉJOV, 2014, p. 461). Desprecio posiblemente potenciado por las habladurías desatas por las falsas cartas de Fiódor. De repente se escucha el disparo del suicidio de Voinitski. Elena decide huir. ¿Qué quería acentuar Chéjov con todo este desarrollo? El suicidio de Voinitski no parece plenamente justificado, una vez que Serebriakov había dicho que no vendería la finca si su cuñado no quisiera. ¿Por qué se suicida, entonces? ¿Un conflicto interior? ¿Por las cartas de Fiódor, cuyo mal entendido se hubiera podido solucionar? ¿Por qué la acumulación dramática incide por triplicado Serebriakov, Sonia y Elena - sobre el médico Jrushov? ¿Qué gana la obra con eso, intriga? La acumulación de los hechos anteriores se disipa en la figura del Fauno: ésta nada tiene que ver con la muerte de Voinitski.

En Tío Vania la condensación es mucho más poderosa. Ya no hay personajes que no hacen más que repetir dramáticamente vínculos circulares del "amor no correspondido". Si en El Fauno habían pasado dos semanas desde el acto anterior, en Tío Vania sólo sabemos que estamos en septiembre, que el otoño ya se acerca. La primera réplica del acto es de Vania: "Herr Professor [...] quiere revelar algo al mundo" (CHÉJOV, 2013, p. 168). Elena dice que se aburre en la finca y Sonia le dice que hay mucho trabajo para hacer por si su madrastra se quiere ocupar de alguno, como ir a enseñar, ya que Elena es profesora. Sonia también le comenta que el médico Astrov prácticamente se mudó a la finca de los Serebriakov. Vania le recomienda a Elena que se deje enamorar, que se relaje, y en señal de paz irá a buscarle unas rosas y sale. Escena dos: Sonia le confiesa a Elena que todos en la finca ya saben que ella ama a Astrov. Elena entonces le ofrece ayudarla: le preguntará a secas a Astrov si él quiera a Sonia; si dice que no, deberá irse de una vez. Elena por compasión a su hijastra se pone en una verdadera encrucijada. Ella no necesita preguntarle a Astrov qué siente él. Todos 
lo saben muy bien. Ella quiere convencerlo a que él acceda a casarse con Sonia, aunque sea sin amor. Es un deseo cargado de contradicciones y atravesado por su propio deseo de estar con el médico. Escena tres: Astrov entra a pedido de Elena y trae unos mapas de los bosques que estuvo pintando para mostrar la degeneración predatoria que sufre la geografía de la zona. Elena no tiene condiciones de pensar en toda la argumentación política de Astrov sobre la conservación de los bosques y saca el tema de Sonia: “¿Le gusta como mujer?" (CHÉJOV, 2013, p. 173). Astrov niega. Elena entonces cumple: le pide que se vaya de la casa. Astrov le dice: "Usted sabe perfectamente bien a qué vengo aquí todos los días" (CHÉJOV, 2013, p. 173). Le pregunta a Elena dónde se seguirán viendo y le pide un beso. Ella se resiste pero él logra besarla. En ese momento entra Vania con un ramo de rosas y ve la escena. Elene le pide a Astrov que la deje y ve que Vania está en la puerta observando. Elena le grita a Vania que hoy mismo se quiere ir de la finca.

La cuarta escena del tercer acto: Serebriakov anuncia ante todos que quiere vender la finca. Vania se indigna, tal como en El Fauno, con los mismos argumentos. Sin embargo, esta escena se da con una acumulación especial de Vania: viene de ver a Elena besarse con Astrov. Esa condensación potenciadora permite que el personaje entre en un terreno desconocido porque se sobreponen casi al mismo instante dos planos de significación: el amor y la finca. Son muy cómicas las dos réplicas de la madre de Vania, María Vasilievna: "No contradigas a Alexandr [Serebriakov]. Créelo, él sabe mejor que nosotros lo que está bien y lo que está mal" (CHÉJOV, 2013, p. 177). Vania le grita a su cuñado: "¡Escribes sobre arte, pero no entiendes nada de arte! ¡Todos tus trabajos, que yo amaba, no valen ni un cobre! ¡Nos has embaucado!” (CHÉJOV, 2013, p. 178). Elena también grita que se quiere ir ahora mismo de ese infierno. Y Vania, desesperado, tiene que volver a oír de su madre que obedezca a Serebriakov. Vania sale y su madre lo sigue. Serebriakov pide que alejen a Vania. Sonia lamenta que con Vania siempre trabajaron duro para la familia. Elena le a su marido pide que se reconcilie con Vania. Salen Elena y Serebriakov. Cuando todo parece tranquilizarse un poco se escucha un tiro. Entran corriendo Serebriakov seguido 
por Elena y Vania que forcejean por el revólver. Vania le había disparado a su cuñado y erró el tiro. Vania vence a Elena y le dispara a Serebriakov una vez más y erra. Elena grita que la lleven de ese lugar de una vez.

Si comparamos con El Fauno, donde Vania se suicida por hechos de cinco escenas antes, en Tío Vania no hay suicidio, sino un intento de asesinato que parece mucho más orgánico y justificado con la acumulación lograda dramáticamente. El cuarto acto de Tío Vania no coincide en nada con el de El Fauno y empieza con una conversación acerca de un posible suicidio de Vania. Entran Astrov y Vania. El médico le exige que devuelva el franco de morfina que robó de su estuche.

Astrov (A Vania): Has sacado de mi botiquín un franquito de morfina. Escucha, si a toda costa quieres suicidarte, entonces ve al bosque y pégate un tiro allá. Pero devuélveme la morfina; si no, empezarán a hablar, a hacer conjeturas, creerán que yo te había dado... Ya tengo bastante con tener que hacerte autopsia... ¿Crees que es divertido? (CHÉJOV, 2013, p. 184)

Entra Sonia y le pide a Vania que devuelva el frasco de morfina. Vania obedece. El suicidio, por lo tanto, se transforma en potencia dramática para crear una situación teatral nueva. Es un tema de conversación, un riesgo contra el que los personajes deberán enfrentarse. Hay que tener coraje para suicidarse, le sugiere Astrov a Vania. Voinitski es tan frágil interiormente que no tiene coraje ni siquiera para suicidarse. Esto lo torna mucho más complejo e interesante para actuarlo. Por un lado, su vínculo apasionado hacia Elena, por otro, la falta de esperanza que conlleva esa no correspondencia. Por un lado las frustraciones de no haber trascendido el mundo del campo, por otro, la imperiosa necesidad de hacerlo por sentirse moralmente esclavizado y habitado por esas tareas. Esas contradicciones son indefinibles e innumerables; están abiertas a cada actor, a cada conjunto de hipótesis de una determinada puesta en escena, a cada vez que se la representa y se la juega. La condensación sigue reverberando, disociando, buscando nuevos límites e interpretaciones. El acto termina con diálogos 
reconciliadores entre Astrov, Elena, Vania y Serebriakov. Todo volverá a ser como antes. Sonia y su tío se dan cuenta de cómo abandonaron las tareas cotidianas de la finca. Y Sonia, finalmente pronuncia su esperanzador discurso hacia Vania: "Descansaremos... Descansaremos" (CHÉJOV, 2013, p. 190).

\section{(IV) La condensación como un desborde del género teatral: Chéjov entre el drama y la comedia}

¿Podríamos afirmar que Tío Vania es una comedia? ¿O más bien un drama con requintes de tragedia? ¿Es realismo, costumbrismo o más bien grotesco? ¿Quién define los límites y las zonas grises de los géneros de una obra tan clásica? ¿Cómo pensar las fonteras de género dramático si la propia obra de Chéjov nos indica una producción mucho más cercana a la comedia y al grotesco? (CAVALIERE, 2009). En las dos últimas obras que Chéjov trajo al público vemos un avance considerable de su estilo. La idea de "drama" que aparece como subtítulo en Las tres hermanas (1903) no debería sorprender o condicionar a un lector, actor, director o espectador. En esta obra, la construcción de personajes trae mucho más especificidades si tenemos en cuenta la evolución de los personajes de las obras anteriores.

Las tres hermanas tiene cuatro actos marcados por acontecimientos mucho más acotados que en las obras anteriores. Esa acotación profundiza no sólo un acontecimiento en particular, sino que además nos trae una profundidad marcada por otros acontecimientos ya acumulados en la trama. En el primer acto, nos enteramos, en primer lugar, que en ese día se cumple un año de la muerte del padre de las tres hermanas: Olga, Masha e Irina, que sueñan con volver a Moscú, ciudad donde nacieron. Olga, Masha e Irina tienen un hermano: Andréi. En segundo lugar, Andréi en ese acto, ya al final, pide en privado a su novia Natasha en casamiento. Es muy posible que Natasha ya estuviera embarazada. Las características de los cuatro hermanos están especificadas al menos a grandes rasgos: Olga es fea, inteligente, y cumplidora; Masha es bella y provocadora; Irina es bella, joven y soñadora; Andréi es deprimido y un poco 
obeso. En tercer lugar, el acto se organiza por ser el día de la llegada del teniente coronel Vershinin que ocupará el mismo cargo que el fallecido padre de las tres hermanas. La brigada militar se instaló en esa ciudad hace algunos años, pero todos son de afuera y viven a merced de tener que irse cuando el gobierno lo disponga. Masha es esposa de Kuliguin, profesor del Liceo donde también trabaja Olga, la más grande de las tres. Conocemos también al médico militar, Chebutikin, que está cerca de la edad jubilatoria y vive en la casa de los hermanos alquilando una habitación. En cuarto lugar, Irina, la más joven de las hermanas, anuncia su vigésimo cumpleaños, por lo que lodos la felicitan. Irina es cortejada por el inseguro barón y teniente Tusenbach. Quinto: Masha y Vershinin se enamoran al conocerse, pese a que el teniente sea casado y tenga dos hijas, siendo esto de público conocimiento. En este acto, conocemos también a dos personajes muy particulares aunque secundarios: el ujier Ferapont que trabaja para Andréi, que es bastante sordo y proporciona situaciones graciosas por su condición, y el siniestro Sonoli, capitan segundo, que frecuenta la casa de las hermanas y que tiene un ácido humor negro aunque parezca tímido por sus breves intervenciones. Son personajes que generan extrañamiento y dan vida a la totalidad de vínculos en juego. Por lo tanto, con acontecimientos muy puntuales y una sobreposición de coincidencias como el aniversario de la muerte del padre de los hermanos y el cumpleaños de Irina, así como el casamiento entre Natasha y Andréi, y la llegada de Vershinin y el casi inmediato enamoramiento con la mal amada Masha que se casó tan solo a los dieciocho años. Los pretextos conmemorativos aliados a acontecimientos de envergadura exaltan la lógica de los personajes y nos muestran los vínculos, deseos y frustraciones en acción. Esta sobreposición de tensiones y acontecimientos es la acumulación dramática.

El segundo acto de Las tres hermanas se enmarca en un "contexto liminal" (RAUSCHENBERG, 2016), a saber, el carnaval: los habitantes de la casa esperan la visita de "las máscaras". Entre el primero y el segundo acto pasó un año y diez meses. Lo inducimos por la lógica de los personajes. Natasha ya tiene el bebé con Andréi y vive en la casa de los hermanos. Como es invierno, Natasha le plantea a Andréi que ha habitación de Irina es la mejor de la casa para el bebé. 
Irina debería mudarse a la habitación de Olga. Andréi, que antes estudiaba y parecía tener alguna esperanza de ser profesor universitario, ahora tiene un cargo en el consejo provincial local y es ayudado por el sordo Ferapont. Vershinin le declara amor a Masha. La mujer de Vershinin intenta suicidarse envenenándose sin éxito. Masha, irritada, maltrata a la anciana sirvienta Anfisa. Tusenbach se muestra interesado en Irina, que ahora trabaja en el Telégrafo local. Tusenbach se quiere casar con Irina, pero ella no lo ama. Irina sabe que no tiene muchas opciones en esa ciudad: Irina sueña con irse a Moscú, pero ese sueño cada vez se aleja más. Tusenbach sabe que no tardará mucho en ser reubicado en otro frente militar, por lo que decide abandonar el ejército para tener una profesión y poder casarse con Irina. Natasha le exige a Andréi que cancele la fiesta de las máscaras para que su hijo Bobik pueda dormir tranquilo. Ya al final del acto, el siniestro Soloni declara su amor por Irina. Irina se enoja y lo echa de la casa. Sin embargo, Soloni le avisa: "Por la fuerza no se consigue ser amado... pero no habrá rivales felices... No los habrá... Le juro, por todos los santos, que a mi rival lo mataré... ¡Oh, mi maravillosa!” (CHÉJOV, 2013, p. 241). Esta amenaza acumula tensión dramática en Irina porque apenas sale Soloni entra Natasha y le exige a Irina que deje su cuarto a Bobik y se vaya a la habitación de Olga. En seguida entra la sirvienta y le anuncia en secreto a Natasha que Protopópov la espera. Es su amante. Olga le avisa a Irina que Andréi perdió doscientos rublos jugando a las cartas y en la ciudad todos hablan de eso.

En el tercer acto todas las acciones están condicionadas por un acontecimiento excepcional: el incendio que abarcó y destruyó toda una manzana de la ciudad. No sólo los bomberos, sino los militares y los demás ciudadanos están movilizados en asistir a los damnificados, algunos de los cuales están adentro de la casa de las hermanas. Estamos en verano, un año y medio después del acto anterior. Natasha ahora ya tiene dos hijos: Bobik y Sófoshka. La sirvienta Anfisa ya es una anciana y tiene dificultad en hacer tareas que le exigen fuerza y en la situación de emergencia se siente mal. Natasha, miserable y mezquina, sólo se preocupa por si sus hijos se contagiarán gripe de los damnificados. En su irritación, Natasha insulta Anfisa y le grita Olga: “iNo comprendo para qué tienes a 
esa vieja!" (CHÉJOV, 2013, p. 245). Olga se enoja con Natasha que le retruca que tiene el manejo de la casa. Olga ahora es directora del Liceo. Kuliguin, el marido de Masha, le dice a Olga que debería haberse casado con ella en vez de Masha. Pero esa declaración no tiene mayores consecuencias. Ambos trabajan juntos y Masha está cada vez más distante de su marido. Vershinin anuncia que van a trasladar a toda la brigada a otra ciudad, pero no sabe adónde. El médico Chebutikin se emborracha en vez de ayudar a los damnificados. Todos están tristes por el traslado y el borracho Chebutikin anuncia que Natasha es amante de Protopópov, cheje de Andréi en el consejo. Soloni aparece e Irina lo echa. Tusenbach ya no es militar y anuncia que se irá a trabajar a una fábrica de ladrillos y espera que Irina lo acompañe. Masha le comenta a su marido y a Irina que Andréi ha hipotecado la casa y que Natasha se apoderó de todo el dinero restante. La casa es te los cuatro hermanos. Andréi tenía deudas por el juego. Irina sabe que si depende de su familia jamás volverá a Moscú. Por primera vez todas las hermanas entienden que ya no volverán a Moscú. Masha les confiesa a sus hermanas que ama locamente a Vershinin. Finalmente Andréi aparece para recriminarle a sus hermanas que tratan mal a Natasha. Sobre la hipoteca, Andréi se escuda en que las solteras reciben una pensión del gobierno y él recién hace poco tiempo tiene un trabajo estable.

El cuarto acto, en el otoño siguiente, se organiza en dos ejes de acción: el primero es la despedida de la brigada que finalmente se retira de la ciudad. EI segundo es el duelo entre Soloni y Tusenbach. Fedótik anuncia que Soloni es el único que se irá en balsa; los demás se van con la tropa. El médico Chebutikin, de muy buen humor, anuncia que también se irá pero que volverá al año siguiente porque ya se podrá jubilar. Irina, alterada, increpa a Chebutikin para que le cuente que sucedió el día anterior entre Soloni y Tusenbach cerca del teatro. El propio Tusenbach es quien impide que Irina se entere del duelo. Tusenbach cayó en la provocación de Soloni y lo retó a duelo. Chebutikin le sigue el juego a Tusenbach. Irina cuenta que mañana se casará con Tusenbach y que en seguida se mudarán a la fábrica de ladrillos. Olga se ha mudado al liceo con Anfisa. Masha le pregunta a Chebutikin si él amaba a su madre. En el acto anterior el médico ya lo había 
insinuado, y ahora lo confirma. El médico, nervioso, les dice a Masha y a Andréi que Tusenbach y Soloni duelarán. Soloni viene a buscar a Chebutikin para que oficie de médico en el duelo. Irina, angustiada, quiere saber qué pasó entre Soloni y Tusenbach, que le contesta que mañana serán felices. El prometido le dice que ella no lo quiere. Irina contesta: "Eso no está en mis manos. Seré tu mujer, fiel y sumisa; pero amor no hay" (CHÉJOV, 2013, p. 264). Tusenbach le dice que no ha podido dormir esa noche y se despide de ella. Irina le pide ir con él. Tusenbach le dice que no y pide que le preparen un café. Vershinin viene a despedirse de Masha y Olga intermedia la situación. Se besa apasionadamente y Masha no lo quiere dejar ir. Olga la contiene. Masha llora fuertemente. Kuliguin aparece y ve a su mujer llorando y trata de calmarla, como si ignorara el motivo del llanto. Cuando Masha se va calmando con Olga y Kuliguin se escucha un disparo. Natasha dice que a su criada que su hija Sofoshka se queradá un rato con Protopópov y Bobik se riá a pasear con Andréi. No se puede entender si eso significaría que Sofochka es en realidad hija del amante Protopópov. Entra Chebutikin y anuncia que Tusenbach ha muerto en el duelo. Irina llora. Se escucha la música que despide a los militares de la brigada. Irina y Olga se abrazan y hablan sobre la necesidad de tener esperanza y trabajar, recordando un poco el discurso final de Sonia a Voinitski en Tío Vania.

¿No tendría Las tres hermanas momentos de comedia, por así decirlo? El diálogo entre Andréi y Ferapont que no escucha bien e irrita a su interlocutor que termina cambiando de tema y hablándose a sí mismo, la complicidad del decadente y desilusionado Andréi con el hecho de que su mujer es amante de su propio jefe, el humor ácido de Soloni, el personaje borracho de Chebutikin en una emergencia humanitaria hablando chismosamente de la vida de Natasha, la indefinición de la actitud de Tusenbach ante la inminencia del duelo - honor por amor propio o suicidio por desamor de Irina - entre otros pasajes, sugieren que el drama también se abre a la risa. ¿Cómo se abre? Lo definirá el director y los actores. El nivel de condensación que tiene Las tres hermanas permite muchos abordajes teatrales. Representar Las tres hermanas puede llevar a un abordaje paródico: son muchas sobreposiciones de significación para detenerse en la mera 
verosimilitud realista o naturalista. Como sostiene Peter Szondi, el drama es lo absoluto: "El drama es una dialéctica cerrada en sí misma y, sin embargo, una dialéctica libre, lista para ser determinada de nuevo a cada momento" (SZONDI, 2011, p. 25). Si un director decide enfatizar el carácter grotesco de los personajes puede crear una totalidad orgánica para la obra aunque algún lector atento del texto no esté de acuerdo. También hay que tener en cuenta que un texto no salta al escenario por arte de magia y "correspondencia" con la idea de un autor, sino que los directores y actores experimentan procedimientos para crear una dimensión de juego muchas veces ajenas al texto, buscando disociaciones a partir de los personajes puestos en una nueva gramática, apenas complementar a la del texto. Raymond Williams, por ejemplo, distingue entre el Chéjov inglés y el Chéjov soviético: en el primero domina el "charme patético", y en el segundo se destaca la solemnidad y la voz "profética del futuro" (WILLIAMS, 2002, p. 190).

En Chéjov podemos hablar de una inadaptación al tiempo que deflagra una curiosa angustia con el espacio. Los personajes se quieren ir y no pueden por motivos aparentemente ajenos a ellos. En ese sentido, el tiempo para los personajes constituye una prisión y no les queda más que fracasar en el intento de evadir los límites de ese espacio. En Las tres hermanas esta angustiante clausura espacio-temporal es muy clara: ninguna de las hermanas, sobre todo Irina, emprende el viaje a Moscú. Chéjov deja claro que ellas reciben una pensión por su padre muerto y además pueden trabajar. ¿Por qué no se van entonces? En El jardín de los cerezos, escrita en 1904, el espacio interpela el pasado de la protagonista Liubov Andréievna y al mismo tiempo impone una irreversible configuración hacia el futuro: la propiedad que le permitió vivir tiempos de prosperidad tiene una fecha de remate gracias a las deudas contraídas. El jardín de los cerezos lleva el subtítulo de Comedia en cuatro actos. ¿Tan diferente es el tono dramático con la obra anterior? Es relativo, pero diremos que no. ¿Y por qué la aclaración "comedia"? Las dos últimas obras de Chéjov exhiben "contrapuntos entre comicidad y presagios angustiantes, matizados por la vaga ilusión a la inminencia de un cataclismo, capaz de barrer la insípida diferencia y el lento arrastrarse de final de un tiempo sin grandes ímpetus, un monótono juego de 
paciencia" (CAVALIERE, 2009, p. 211). Konstantín Stanislávski "se lanzó entusiasmado al montaje que le había fascinado por sus valores literarios y teatrales" (SAURA, 2000, p. 8). Sin embargo, el director y actor ruso subrayó "que Chéjov se había equivocado al adjudicarle género" (SAURA, 2000, p. 8). En una carta al autor, Stanislávski dice que "esto no es una comedia, ni una farsa, como dice usted, esto es una tragedia. Ya oigo cómo usted dice: 'un momento, que esto sí es una farsa'. No, para una persona normal, esto es una tragedia" (STANISLÁVSKI, 1986, carta 9).

En ese conteo regresivo, Chéjov puso en juego, por un lado, personajes más trágicos como Andréievna, sus hijas Varia y Ania, el estudiante Tromífov y de cierta forma el antagonista Lopajin. Andréievna derrocha el poco dinero que le queda con abastadas propinas y limosnas. Pese a una cierta "tragicidad" angustiosa de Ania y Tromífov, ambos personajes aparecen - por lo menos se intuye desde el texto - en ardientes episodios de amor aunque no hablen explícitamente de amor. Esa disociación nos abre a la inmanencia de la interpretación actoral, donde lo que sucede está lejos de lo que es dicho. Por otro lado, el autor trae personajes saltados de vaudevilles del teatro popular como Gáiev (el hermano de Andréievna) que "salpica cualquier diálogo con descripciones de jugadas de billar y pronuncia ante todos una inesperada 'oda al armario"' (SAURA, 2000, p. 3); la institutriz Charlotta Ivánovna es una maniática que habla poco y nada pero lo puede hacer en otros idiomas; el terrateniente decadente Pishchik aparece como un oportunista y parásito; la sirvienta Duniasha es demasiado sensible y reprimida; su hijo, el lacayo lasha, es descarado, arrogante e incluso cruel con otros miembros del servicio y exageradamente servil con sus amos; el empleado de la finca Epijódov, también conocido como "Don Desgracias" gracias a su torpeza, es pedante, solemne, "emplea un lenguaje lleno de rodeos, frases ampulosas y bruscos cambios de tema" (SAURA, 2000, p. 3); y el lacayo Firs, que en razón de su elevada edad también el casi sordo como Ferapont de Las tres hermanas. En El jardín de los cerezos, por lo tanto, el rol cómico de la mayoría de los personajes es primordial. 
En la obra anterior, los cuatro actos se estructuraban en torno a acontecimientos puntuales sobrepuestos. Ya en El jardín de los cerezos la composición de los actos conduce a un gran evento: el remate de la propiedad. Desde luego hay eventos importantes en cada acto: en el primero, llegan Liubov Andréievna y Ania desde París; en el segundo; los personajes están cerca del jardín de los cerezos; en el tercero, están todos en la casa festejando salvo Lopajin y Gáiev que van al esperado remate; y en el último, como en Tío Vania y Las tres hermanas, se da la despedida de Andréievna y sus hijas. Sin embargo, el en recorte temporal de esta obra todo sucede - está condensado - en un verano, pero ese verano carga muchas historias, se juega una venganza oculta, la de Lopajin, nieto e hijo de esclavos de la familia de Andréievna, devenido ahora en un hombre libre de negocios y que se da el lujo de rechazar por omisión la mano de Varia, la hija adoptiva de Andréievna. Aquí se repite de cierto modo la trama del vínculo entre Ivanov y Sasha: si se casaran se arreglaría todo, sin embargo Lopajin parece querer tomarse el gusto de dar vuelta la estructura social y quedarse con la propiedad de sus ex señores. Sin embargo, no hay explícitamente un plan de venganza como pudiera parecer analizando el final de la obra a la ligera.

En el primer acto, Lopajin se queda en la casa de Andréievna para esperarla y proponerle un negocio: lotear el terreno del jardín de los cerezos, talarlo (es decir, destruir todos los árboles centenarios, e inclusive la decadente casa-palacio), y construir casas para alquilarle a los veraneantes ya que el río está al lado y la construcción del ferrocarril ha traído cierto desarrollo a la zona. Lopajin sería una suerte de socio del emprendimiento y Andréievna ganaría un buen dinero para salvar la propiedad del remate judicial y obtener ganancias por la renta. Pero para entrar en esa trama no alcanza con entender de modo intransigente las tensiones de clase como si el rol de los personajes representara o simbolizara un cálculo social (LUKÁCS, 1977; RAUSCHENBERG, 2017). Es cierto que en ninguna de las obras anteriores la "movilidad social", por así decirlo, fue un tema central. Elena Andréievna, de Tío Vania, era de origen aristocrático, pero solo con eso no bastaba para justificar que Astrov y Voinitski la desearan 
locamente. Tenemos que abordar los personajes y los vínculos. Como argumenta Peter Szondi, el drama siempre es primario, y su tiempo es siempre el presente. "Lo que no se traduce en absoluto a una situación estática, sino solo en el modo particular del decurso temporal dramático: el presente pasa y se torna pasado, pero como pasado no se hace más presente en escena" (SZONDI, 2011, p. 27).

Duniasha le cuenta a Lopajin que el "Don desgracias" de Epijódov le ha pedido a en casamiento. Duniasha conoce a grandes rasgos la situación económica y algún posible destino de la finca y de su trabajo en razón del impostergable remate. Cuando ella escucha llegar a Andréievna se desmaya estrepitosamente. Nos enteramos que la hija adoptiva de Andréievna, Varia, se quedó en la finca, mientras que lasha (hijo de Duniasha), Ania (de diecisiete años) acompañaron a la Liubov a París. Ania: "hace seis años murió mi padre; un mes más tarde se ahogó en el río mi hermanito Grisha, un hermoso chiquillo de siete años. Mamá no lo pudo soportar, se marchó de aquí, se fue sin volver la cabeza... Si ella supiera cómo la comprendo" (CHÉJOV, 2013, p. 280). Las muertes del marido y de Grisha, por lo tanto, fueron un punto de quiebre crucial para Andréievna. Por otro lado, Lopajin reconoce la ayuda que Andréievna le dio que le permitió salir de su condición social inferior. Lopajin: "Mi padre era siervo de su abuelo y de su padre; pero usted, usted personalmente hizo tanto por mí que lo olvidé todo y la quiero como si fuera de mi familia, más que a mis familiares" (CHÉJOV, 2013, p. 282). La réplica siguiente de Andréievna ignora totalmente la declaración afectiva de Lopajin. Andréievna: "No puedo quedarme sentada, no aguanto... (Se levanta de un salto y se pasea, muy agitada.) No sobreviviré a esta alegría... Ríanse de mí, soy una tonta... ¡Armarito mío! (Besa el armario.) ¡Mesita mía!" (CHÉJOV, 2013, p. 282). Es como si Andréievna no aceptara nivelarse con Lopajin. Esta dialéctica de dominación y distanciamiento entre Andréievna y Lopajin es el motor dramático de El jardín de los cerezos. Gáiev y Andréievna tienen como principal marca de status social el jardín, pero está improductivo hace años. Talar el jardín sería destruir la posición social, sobre todo lotearlo y dejarse arrastrar por la muchedumbre ansiosa por un pedacito de terreno para veranear. 
En el segundo acto, nos enteramos que Andréievna después de enviudar, se volvió a enamorar de un hombre que la despojó de todo. Ese hombre, que vive en París, se había enfermado y ella lo cuidó tres años. Sin embargo, una vez curado, él la abandonó, la dejó por otra mujer. Andréievna intentó envenenarse. No obstante, ese hombre le escribe de París un telegrama pidiéndole perdón y que vuelva porque se ha enfermado otra vez. Por otra parte, Lopajin insiste con su proyecto de las casas de verano en el jardín de los cerezos, oferta que vuelve a ser categóricamente rechazada por Gáiev y Andréievna: "Es tan vulgar". Lopajin pierde la paciencia. En el tercer acto llega el día del remate, veintidós de agosto. En la casa hay una pequeña fiesta con una orquesta de judíos. Andréievna espera ansiosa la llegada de Lopajin y Gáiev con la noticia del futuro de la finca. Su madre Yaroslavl le dio quince mil rublos para comprarla a su nombre en el remate. El terrateniente amigo, anciano y decadente Píshchik pide algunos rublos prestados para pagar la cuota de la hipoteca de su propiedad. Andréievna le comenta al joven estudiante Trofínov su situación amorosa deplorable con el hombre de París: "Es una piedra atada a mi cuello, me hundo con él, pero amo a mi piedra y no puedo vivir sin ella" (CHÉJOV, 2013, p. 308). Finalmente llegan Lopajin y Gáiev: fue un remate peleado con Drigánov, pero la finca la compró Lopajin por noventa mil rublos. Lopajin, enceguecido por el poder: "¡Compré la propiedad donde mi abuelo y mi padre fueron esclavos, donde no les permitían entrar ni en la cocina!" (CHÉJOV, 2013, p. 314).

En el cuarto acto ya es octubre y está marcado no sólo por la despedida de Andréievna y su familia de su ex propiedad, sino también por la urgencia en llegar a tiempo para tomar el tren. Se escuchan los golpes de hacha en los árboles. Andréievna irá a París a ver a su amado enfermo y allí vivirá con el dinero que su madre había destinado a comprar la finca. Sin embargo, su angustia sigue porque no es mucho dinero. El viejo Píshchik alquiló sus tierras a unos ingleses que encontraron allí barro blanco, así que no más deudas e hipotecas. Lopajin sigue su vida de empresario y parte en el mismo tren rumbo a Járkov. Más allá de que el lector o espectador de la obra pueda intuir sin sorpresa el final de la obra, es interesante el juego escénico que se propone desde la 
dramaturgia. La urgencia del tren impone tiempos, coreografías, apuros, pausas angustiosas demasiado largas, conversaciones desnecesarias, reiteraciones de juegos de lenguaje más acelerados como, por ejemplo, el reproche de Ania y Varia a su tío Gáiev para que se calle, pero él siempre remata sus conversaciones cantando jugas de billar. Ya al final, cuando todos ya han salido, aparece el viejo Firs que se dirige a una puerta y comprueba que está cerrada: "Se han ido... (Se sienta en el diván.) Se olvidaron de mí... No importa... me quedaré aquí sentado... pero seguro que Leonid Andréievich [Gáiev] no se ha puesto el gabán de piel; se fue con el tapado. (Suspira preocupado.) Y yo no estaba para advertírselo... ¡Ah, la juventud, la juventud! La vida pasó, como si uno ni hubiese vivido... (Se acuesta.) Me recostaré... No tienes fuerzas, no te ha quedado nada, nada... ¡Eh, tú... torpe! (Está tendido, inmóvil.)" (CHÉJOV, 2013, p. 325).

La acumulación dramática es muy particular en El jardín de los cerezos. Por un lado, Andréievna y toda su familia viven una angustia de algo inevitable: el remate, la expropiación de sus tierras, la diáspora familiar, el fin de una época ancestral plagada de privilegios. El retorno de Andréievna indica que hay una situación económica que resolver. Ella además toma una decisión sentimental de regresar a París. La opción latente de resolver esa situación es el casamiento entre Lopajin y Varia. ¿Pero por qué Lopajin no consigue pedir la mano de Varia y se traba en la acción en dos oportunidades? Esta omisión aporta una acumulación dramática que estalla con el discurso de Lopajin desbordado después de comprar la finca en el remate. La segunda omisión de Lopajin de pedirle la mano a Varia es ya en el acto final, es decir, dos meses después del remate. O sea: todavía había esperanzas, hasta minutos antes que saliera el tren. Gáiev, después del remate, empezó a trabajar en el banco del pueblo y asumió, por lo tanto, una nueva vida y nueva condición social. Ania se dispone a ingresar en el Liceo para seguir alguna carrera posteriormente. Por lo tanto, la estrategia de acumulación dramática en esta obra, viene del recorte temporal en razón del gran evento: el remate. Eso incluye la llegada de Andréievna, su reencuentro con Lopajin, Gáiev, Varia y los trabajadores de la finca. Pero su llegada es ya parte de un proceso en marcha ocasionado por el abandono de la función económica de la 
finca y el acúmulo de deudas. La despedida, con la muerte patética de Lirs representa la muerte de un modelo social y la asunción de otro, ya sea el poder del emprendedor Lopajin o el sistema financiero. Una decadencia conlleva hacia una asunción.

\section{Notas conclusivas}

Buscamos en este quizás un poco extenso artículo reflexionar sobre las estrategias de condensación dramática en lo que consideramos aquí las principales obra teatrales de Antón Chéjov, aquellas compuestas en cuatro actos, por mencionar una característica. En primer lugar, reflexionamos sobre la dialéctica disociación-condensación para situar conceptualmente nuestro objetivo. Vinculamos el procedimiento de la disociación a la noción de rizoma de Félix Guattari y Gilles Deleuze (2002). El procedimiento de la disociación nos lleva a buscar otras gramáticas para desarrollar los materiales dramáticos, a saber, características físicas de los personajes, tiempos históricos ficcionales, espacios disonantes, imágenes compuestas y sobrepuestas que nos alejen de un pensamiento de "causa y efecto", es decir, que nos haga pensar más allá de los condicionantes deterministas y previsibles de las representaciones sociales ya consagradas en otros campos. La disociación nos conduce a encontrar otras síntesis en otras multiplicidades de sentido, nos permite transitar diferentes escalas y distintas conexiones inesperadas, ya sean estéticas, morales, políticas, ya sean introspectivas, concretistas, de poéticas muy particulares, obsesivas y disruptivas. La disociación permite crear el mundo de los personajes e indagar sobre los vínculos entre ellos. Por otro lado, la condensación es una interrupción creativa de ese proceso: es encontrar desde una determinada poética un momento de detener la disociación para permitirle reverberar en otros planos de inmanencia. En el texto teatral, el principal plano de inmanencia es el escenario con los trabajos de dirección y actuación. Buscamos aquí a partir del potencial condensador de las obras de Chéjov indagar sobre la constitución de esos potenciales planos de inmanencia. El texto ya cerrado permite aperturas. Como 
dice Szondi, el drama tiene un tiempo presente. Citamos, inclusive, anecdóticamente cómo Chéjov rechazaba las propuestas de Stanislávski sobre sus textos.

Más allá de esa especificidad en torno al potencial escénico de un texto en particular, nuestra estrategia optó por reconstruir obra por otra las construcciones dramáticas en juego a partir de personajes, vínculos, tramas y recorte temporal. Por una cuestión de tiempo y espacio enfatizamos La gaviota (1896), Tío Vania (1898) (pasando por su primera versión, El Fauno, de 1889) Las tres hermanas (1903) y finalmente El jardín de los cerezos (1904). Nos interesó entrar en las minuciosidades de los personajes para entender las búsquedas de sus mundos, es decir, sus deseos, frustraciones, actividades cotidianas etc. En Platonov hay una búsqueda por desarrollar el círculo del desamor. En Ivanov el desamor conduce primero a la muerte de Ana Petrovna y finalmente al suicidio del propio Ivanov consumido por la culpa. En La gaviota, con más detalles, analizamos ese círculo de simetrías para entender la imposibilidad de que el amor del joven Tréplev sea correspondido por Nina, enamorada de Trigorin. Analizamos Tío Vania teniendo en cuenta una primera versión: El Fauno. Propusimos entender Tío Vania como una suerte de síntesis entre El Fauno y La gaviota para enfatizar cómo Chéjov logró crear una acumulación dramática en torno al personaje de Voinitski. Al ver a su pretendida Elena besarse con el médico Astrov, Voinitski atiende el llamado de Serebriakov para escucharlo decir que quiere vender la finca.

Finalmente, analizamos Las tres hermanas y El jardín de los cerezos entendiendo que en estas obras la construcción dramática de la condensación está elaborada de una manera más consistente, sobre todo teniendo en cuenta el recorte temporal que reconstruyen. La acumulación ya no se basa sólo en el vínculo de los protagonistas, sino también se sustenta en la construcción formal del tiempo y los problemas sociales más profundos del entorno de los personajes. El recorte de tiempo y la sobreposición de situaciones dramáticas agudizan no sólo el conflicto de los personajes, sino que además nos permiten ver dimensiones sociales multicausales en la construcción del drama. En Las tres 
hermanas, cada acto estaba atravesado por una situación dramática particular. En el primer acto se acumulan tres situaciones: era el cumpleaños de Irina, el primer aniversario de la muerte del padre de los cuatro hermanos y la llegada de Vershinin. El segundo gira en torno a la fiesta de máscaras que queda obstruida por Natasha. El tercero se organiza como reacción al incendio y el último la despedida de la brigada y el duelo entre Soloni y Tusenbach, prometido de Irina, traen toda la tensión dramática. En El jardín de los cerezos la condensación dramática en torno al remate judicial de la propiedad potencia los resentimientos de clase de los personajes. Chéjov creó una tensión dramática entre dos personajes: por un lado, Andréievna, heredera y dispilfarrona y, por otro, el prolijo y ambicioso Lopajin, que además es hijo y nieto de ex esclavos de la finca de Andréievna. La construcción del tiempo se inicia con la llegada de la protagonista y tiene como momento de clímax el anuncio final de que en el remate el comprador fue Lopajin, quien además rechaza por omisión casarse con Varia, la hija adoptiva de Andréievna.

Recebido em 28/02/2020

Aceito em 06/04/2020

\section{Referências}

CAVALIERE, Arlete. Tchékhov: da farsa ao drama. En: Teatro russo: percurso para um estudo da paródia e do grotesco. São Paulo: Humanitas, pp. 179-222, 2009.

CHEJOV, Antón. Teatro completo. Traducción de Galina Tolmacheva. Adriana Hidalgo: Buenos Aires, 2013.

CHEJOV, Antón. Teatro completo. Losada: Buenos Aires, 2014.

DELEUZE, Gilles \& GUATTARI, Félix. Mil mesetas: Capitalismo y esquizofrenia. Valencia: Pre-Textos, 2002.

GAMBARO, Griselda. Penas sin importancia. En: Teatro 5, Buenos Aires, La Flor, 2008. 
GUINSBURG, Jacó. Stanislávski e o teatro de Arte de Moscou. São Paulo: Perspectiva, 1985.

LUKÁCS, George. Se trata del realismo. En: Materiales sobre el realismo. México DF: Ediciones Grijalbo, 1977.

RAUSCHENBERG, Nicholas. Liminalidad como teatralidad: de Esquilo a Aristófanes. Revista Antares Letras e Humanidades, vol. 8, n 16, pp. 98-125, 2016.

RAUSCHENBERG, Nicholas. Lukács, Brecht y Bloch. Notas sobre el debate 'Realismo/Expresionismo'. Revista Anacronismo e Irrupción, IIGG/UBA, Vol. 7, n० 13, pp. 146-172, 2017.

SAURA, Jorge. El enigma de la cuerda floja. Acotaciones, Resad, $n^{\circ} 4$, enerojunio, pp. 1-17, 2000.

STANISLÁVSKI, Konstantin. Mi vida en el arte. Barcelona: Alba, 2013.

STANISLÁVSKI, Konstantin. Trabajos teatrales. Correspondencia. Buenos Aires: Quetzal, 1986.

TROYAT, Henry (1986). Chekhov. New York: E. P. Dutton.

SZONDI, Peter. Teoria do drama moderno. São Paulo: Cosac Naify, 2011.

WILLIAMS, Raymond. Tragédia moderna. São Paulo: Cosac Naify, 2002. 